Commission 1983-85 (HMSO, 22 October 1985), it is stated that ". . . in some cases it has been necessary to defer issuing a second opinion until genuine involvement of other disciplines has been initiated..." (section 11.5(c), page 40). It is not necessary to be a cynic to identify the Kafkaesque bureaucracy behind that statement.

There is a clear anomaly in the legal requirement for such an opinion in the absence of universal clinical indications for the involvement of a further professional as defined.

It is not clear in Dr West's article whether the opinions on ECT given by the social worker and the nurse were volunteered or sought; if the latter this is surely improper-the SOAD should not seek opinions which if given would be outside the professional competence of those consulted. That questions of this type are asked on occasion can be substantiated from my own experience. A physiotherapist was asked by the SOAD in one hospital where I have worked if a particular patient should be given ECT; she rightly considered that she should not have been asked for this opinion.

Birch Hill Hospital

Rochdale

\section{Increased demand for psychiatric beds in the London metropolitan area}

DEAR SIRS

Due to the increased demand for psychiatric beds in the London metropolitan area, duty psychiatric registrars attending to emergencies, either in the Accident and Emergencies department or brought in by the police under Section 136 of the Mental Health Act, often spend hours on the telephone trying to find available beds for suitable patients. In central London, this problem is made worse by itinerant patients from distant parts of the country attracted to the 'inner city'.

Almost all psychiatric hospitals in London operate on a 'catchment area' basis and it is usually quite simple to ascertain a patient's catchment area hospital by ringing the Maudsley Emergency Clinic (703 6333) any time of the night or day, provided one has an address. The problem arises when these hospital beds are full. It then becomes a test of endurance trying to convince another hospital to accept such patients temporarily.

This sort of 'crisis' could be alleviated to some extent if representatives from various London hospitals could meet and agree to form a 'Bed Bank' such as other medical and surgical services sometimes have. Such a scheme would necessarily involve the larger mental hospitals situated in the Greater London area, which usually have more available beds. Most hospitals would find an arrangement of this sort mutually beneficial.

Pradeepta Chowdhury

420 East 70 Street

New York, USA

(Formerly Registrar, University College Hospital, London)

\section{Guidelines on the prescribing of benzodiazepines}

DeAr Sirs

We are endeavouring to produce district guidelines, for both hospital and community use, on the prescribing of benzodiazepines. It is our aim to restrict the use of such drugs to clearly defined clinical needs and to stop the unnecessary, but all too common practice, of routinely prescribing night sedation on general wards.

May we therefore, through the columns of the Bulletin, enquire as to whether any similar guidelines exist elsewhere in the UK.

Any help and information will be greatly appreciated. D. G. RAMSTER

A. J. BARBER

Severalls Hospital

Boxted Road

Colchester, Essex CO4 5HG

\section{Guardianship Orders}

DEAR SIRS

We are writing to ask if any other members of the Royal College of Psychiatrists have experienced difficulty implementing Guardianship Orders (Section 7-10 of the Mental Health Act, 1983).

We have found that Social Services in the Wirral are of the opinion that the Guardianship Order does not allow them to convey a patient from hospital or any other place to the place where the Guardianship Order requires them to live (Section 8(1)). They are thus reluctant to implement Guardianship Orders on patients in hospital or unsuitable accommodation because they feel that the Order as it stands does not provide any mechanism for conveying the patient to the desired residence if the patient is unwilling to go there.

R. BROWN

D. H. MILLER

Arrowe Park Hospital

Upton, Wirral, L49 5PE

\section{Plight of female child psychiatrists}

DEAR SIRS

Dr Hardwick's article on Occupational Agarophobia (Bulletin, July 1987, 11, 230-231) caused a lot of amusement in our overwhelmingly female household but was thought (as with most articles by men) to grossly understate the plight of women in general and female child psychiatrists in particular. I am led to believe that in all but the most exclusive and expensive dress shops there is a communal changing room in which women of all ages can be observed in their underclothes or even totally naked if they happen to be trying on bras and panties. It is apparently at these moments of deshabille that the female child psychiatrist is most likely to be observed or hailed by her most difficult and 